\title{
SUPPLY CHAIN MANAGEMENT IMPLEMENTATION \\ IN THE SPANISH GROCERY SECTOR: \\ AN EXPLORATORY STUDY
}

\author{
CRISTINA GIMÉNEZ ${ }^{\top}$
}

GREL-IET; Universitat Pompeu Fabra*

\begin{abstract}
This paper explores the integration process that firms follow to implement Supply Chain Management (SCM) and the main barriers and benefits related to this strategy. This study has been inspired in the SCM literature, especially in the logistics integration model by Stevens [1].

Due to the exploratory nature of this paper and the need to obtain an in depth knowledge of the SCM development in the Spanish grocery sector, we used the case study methodology. A multiple case study analysis based on interviews with leading manufacturers and retailers was conducted.

The results of this analysis suggest that firms seem to follow the integration process proposed by Stevens, integrating internally first, and then, extending this integration to other supply chain members.
\end{abstract}

\section{Key words}

Supply Chain Management, Grocery sector, Logistics integration process.

\footnotetext{
T The author thanks the members of GREL-IET for their comments and suggestions.

Cristina Giménez Thomsen. Departament d'Economia I Empresa. UPF. Ramon Trias Fargas, 2527. 08005 Barcelona, Spain. Phone: 34-935422901. Fax: 34-935421746. E-mail: cristina.gimenez@upf.edu.
} 


\section{Introduction}

Integration of logistics management was identified as the primary challenge of the 1990's to gain and maintain customer loyalty [2] and competitive advantage [3]. The scope of integration has evolved during the last decades, from an internal integration perspective to a supply chain integration approach. During the 1980's some companies initiated an internal integration process because they had recognised the potential savings from integrating the management of the various components of logistics throughout the organisation as a whole [4]. Costs were reduced and service improved by integrating such activities as customer service, transportation, warehousing, inventory management, order processing, production planning and purchasing.

During the 1990's appeared the Supply Chain Management (SCM) concept. SCM is "an integrative philosophy to manage the total flow of a channel from earliest supplier of raw materials to the ultimate customer, and beyond, including the disposal process"[5]. Some companies have already adopted this approach to gain a competitive advantage (cost or value advantage) [6]. Firms have realised that the logistics perspective that considers the company itself, without considering its supply chain members, is not sufficient to gain a competitive advantage: there is the need to consider the supply chain as a whole.

Integration along the supply chain is a topic of interest and importance among logistics managers and researchers because it has been considered a source of competitive advantage. This paper explores the integration process that firms follow to implement SCM; in particular, it has the following primary objectives:

- To obtain an in depth knowledge of the SCM practices implemented in the Spanish grocery sector. 
- To explore which are the main benefits derived from SCM and the major barriers found in its implementation.

Our study will focus on the implementation of SCM in a particular industry: the grocery sector. We have centred our study in one industry because different levels of SCM development may be associated to them. For example, the automotive industry may be very advanced in SCM because the JIT philosophy (which shares many principles with the SCM philosophy) has been present for decades, while the grocery sector may not be so advanced in SCM because not many companies have implemented it yet.

In the literature, there are many studies that consider internal or external integration from the logistics' point of view [7], but very few consider both levels of integration simultaneously [8]. Our contribution to the existing body of knowledge is to consider both levels of integration simultaneously and to obtain an in depth knowledge of the integration process through a multiple case study analysis. Examining perceptions of logistics professionals through deep interviews provides a greater understanding of the logistics integration process.

The remainder of the paper is structured as follows. Section two briefly examines the literature on logistics integration topics; section three describes the research methodology; section four presents the research results; and section five draws conclusions from the research and provides managerial implications from this work.

\section{Literature review}

SCM involves integration, co-ordination and collaboration across organisations and throughout the supply chain. It means that SCM requires internal (intraorganisational) and external (interorganisational) integration. Internal 
integration refers to the coordination, collaboration and integration of Logistics with other functional areas, while external integration refers to the integration of a firm's logistics activities with those of their customers and suppliers [9].

Stevens [10] suggests that companies follow an integration process that goes through different stages. Figure 1 shows that in stage I Logistics is considered just a distribution function, with no coordination with Supply, Production and Marketing. In stage II, there is an integrated logistics concept, where all logistics activities are coordinated. And, finally, in stage III the internal integration achieved in stage II is extended to other supply chain members. This suggests that companies integrate internally first, and then, extend the integration process to other supply chain members.

Figure 1. Logistics evolution: From distribution logistics to supply chain

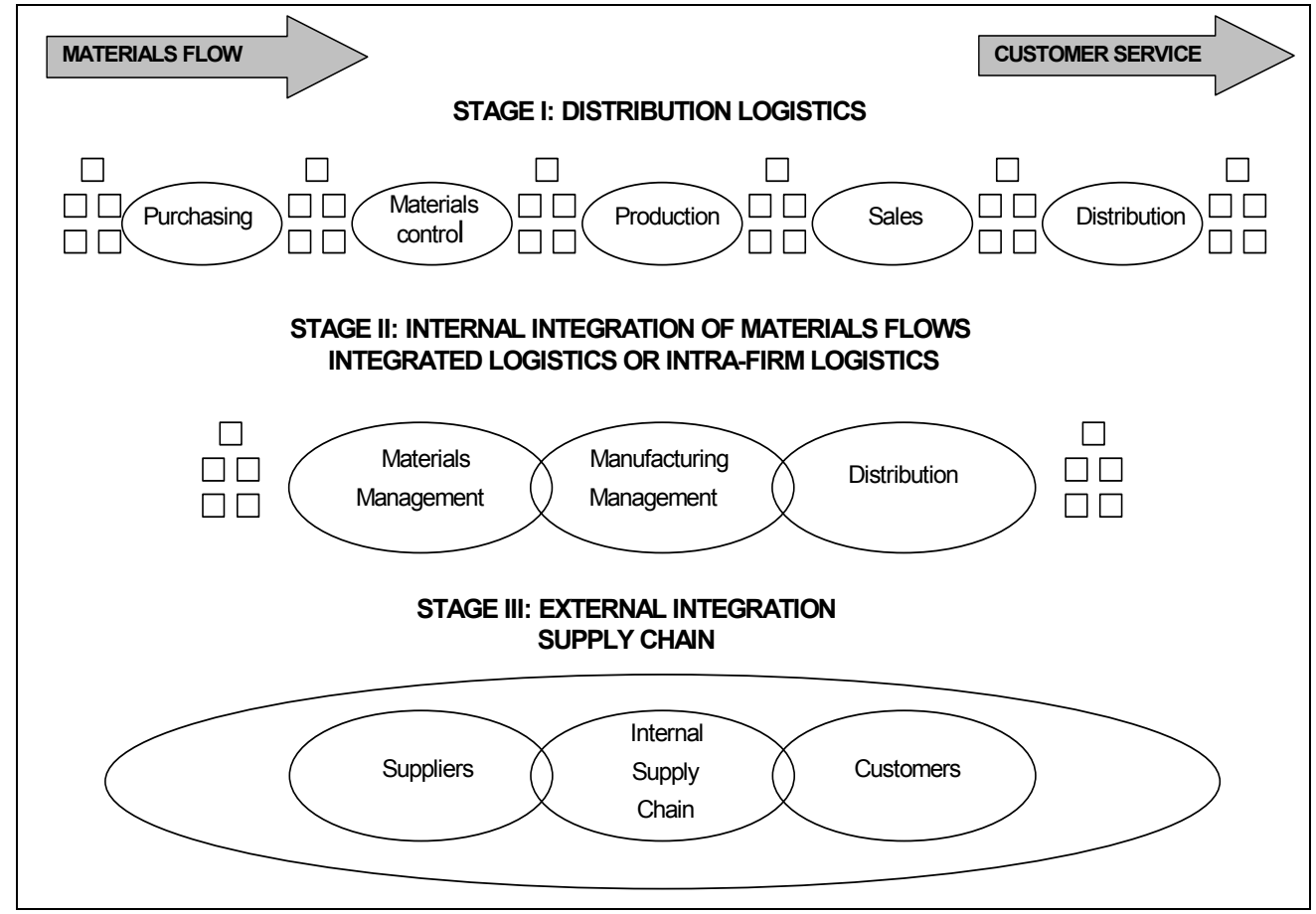

Source: Adapted from Stevens, G.C. (1989): "Integrating the Supply Chain"; International Journal of Physical Distribution and Materials Management; Vol. 19 no. 8; pp. 3-8.

SCM receives a different name depending on the industry where it is implemented. For example, the SCM strategy which attempts to address the 
inefficiencies that have led to excessive inventory and costs at all levels of the grocery supply chain is known as Efficient Consumer Response (ECR). The concept on which ECR is based, actually originated from the Quick Response (QR) strategy, already existing in the textile and apparel industries [11]. And, $\mathrm{QR}$, in turn, is based on the manufacturing Just-In-Time (JIT) concept [12]. The philosophy behind these SCM strategies is to have stock replenishment systems based on demand and to establish collaborating relationships with suppliers.

As stated before, our study will focus on the implementation of SCM in a particular industry: the grocery sector. Therefore, we will focus on the implementation of ECR. ECR was born in the USA in 1992 as a philosophy which objective is the collaboration between manufacturers and retailers with the aim of eliminating inefficiencies, generate economies and offer higher value to customers. In Spain, this philosophy arrived in 1995 with the creation of the Spanish ECR Council.

Spanish retailers and manufacturers have taken as a starting point of ECR the implementation of Efficient Replenishment programs, because they provide the quickest benefits, and this, encourages more companies to implement them. Efficient Replenishment covers activities such as store replenishment, materials flows, inventory control, management of warehousing, and processing and delivery of orders. Within the Efficient Replenishment programs, one of the most implemented is the Continuous Replenishment Program (CRP). CRP is a stock replenishment system related to Vendor Managed Inventory (VMI), where the supplier has the responsibility of self generating orders on the basis of sales and sales forecast and promotion information received from retailers.

The expected benefits derived from the implementation of ECR include lower total system inventories and costs, enhanced consumer value in choice and 
quality of products, and more successful development of consumer-driven products. ECR offers even greater potential: some companies, such as Procter \& Gamble, are projecting revenue increases worth $30 \%$ or more as a direct result of their ECR initiatives [13].

Although ECR can bring these benefits, it is difficult to implement, as it requires organizational and cultural changes: first, it requires integration across different functional units, which have been used to work independently. And, second, it implies moving away from arm's length relationships to partnerships, when for decades, buyers and suppliers of the grocery industry have been used to act as adversaries.

In the literature, there are many studies which consider internal or external integration from the logistics' point of view [14], but only two consider both levels of integration simultaneously: Stank, Keller \& Daugherty [15] and Gimenez \& Ventura [16]. This study shares a similar framework to these studies, considering both levels of integration, but it differs from them in two aspects: one, they use a survey to analyse the integration-performance relationship, while we base our analysis on a multiple case study to obtain an in depth knowledge of the integration process. And, second, they analyse the integration process from only one side of the relationship while we consider both sides (manufacturers and retailers)

\section{Methodology}

Due to the exploratory nature of this paper and the need to obtain an in depth knowledge of the SCM development in the Spanish grocery sector, we have used the case study methodology. This methodology has recently been called for greater employment by operations management researchers [17]. The 
process followed to design and implement this methodology has been adopted from Yin [18].

The complete Spanish grocery supply chain is extremely difficult as can be seen in figure 2. Due to the need of limiting the scope of this paper, it has not been possible to cover all the various facets of this supply chain. The focus of this paper is primarily on the manufacturer-retailer relationship, not considering any other type of relationship within the grocery supply chain. There are many other important elements in this chain such as third party logistics providers, wholesalers, purchasing centres, manufacturers' suppliers and the relationships between them and the elements subject of this study (manufacturers and retailers), but they have not been considered in the scope of this paper.

Figure 2. Supply chain relationships in the Spanish grocery sector

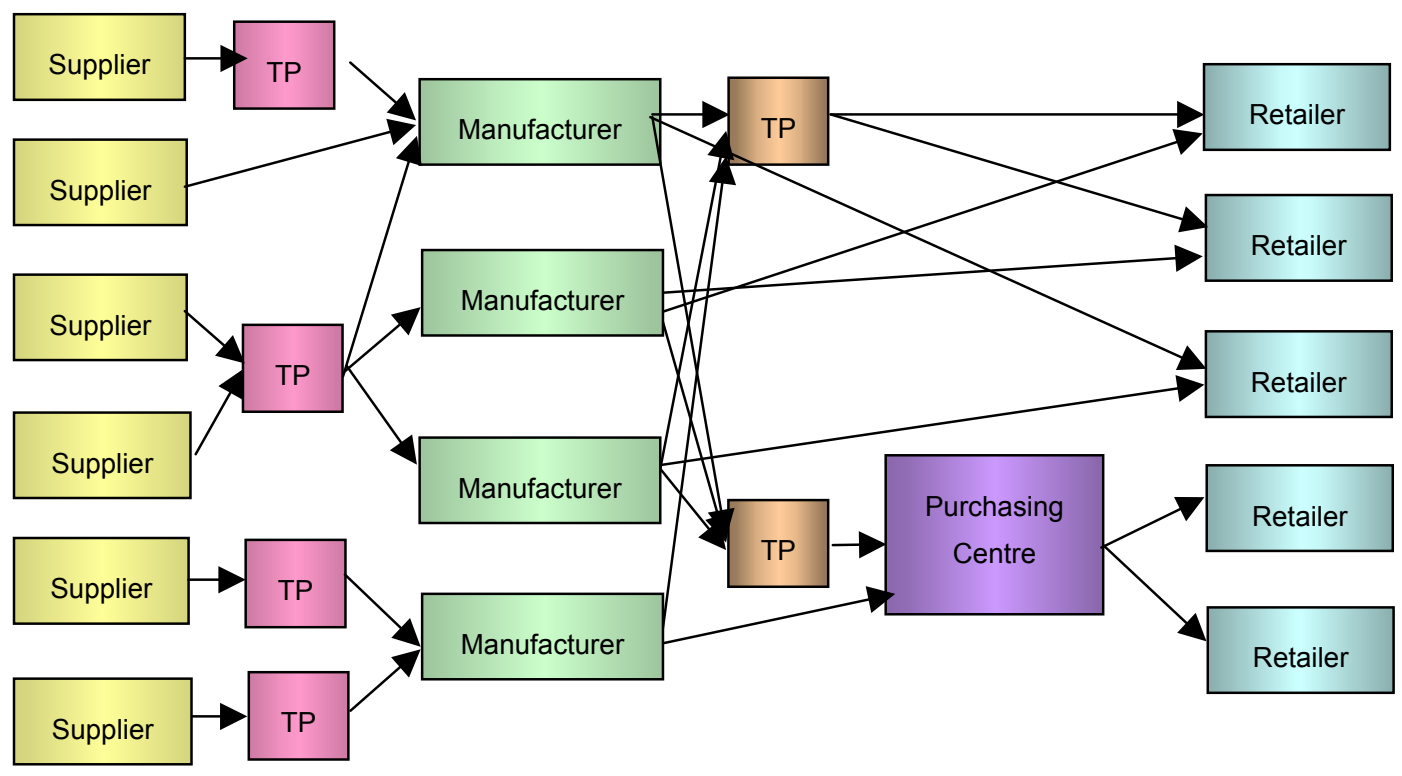

As the focus of this analysis is the relationship between grocery retailers and their suppliers (food and perfumery-detergents manufacturers), interviews with nine manufacturers and six retailers were conducted during the spring-summer of year 1999. Manufacturers were companies leaders or among the leaders in 
different product categories and retailers were selected among the top-12 Spanish retailers (retailers interviewed had a market share of $19,40 \%$ in 1997 , while the top-10 companies had a market share of $45 \%$ ). Among both samples there were companies participating in ECR pilot programs, and companies that were not. Initially, ten manufacturers and ten retailers were contacted, but one manufacturer and four retailers declined to participate in the study. In order to increase firms' participation in the study, we promised all companies to keep them anonymous. Table I shows a brief description of each company participating in the study.

Table I. Companies in the sample

\begin{tabular}{|c|c|c|}
\hline COMPANY & TYPE OF RETAILER/ PRODUCT & MARKET SHARE \\
\hline \multicolumn{3}{|c|}{ RETAILERS } \\
\hline Retailer 1 & Grocery retailer & $1,7 \%$ \\
\hline Retailer 2 & Grocery retailer & $2,1 \%$ \\
\hline Retailer 3 & Grocery retailer & $0,9 \%$ \\
\hline Retailer 4 & Grocery retailer & $7,7 \%$ \\
\hline Retailer 5 & Grocery retailer & $6,2 \%$ \\
\hline Retailer 6 & Grocery retailer & $0,8 \%$ \\
\hline \multicolumn{3}{|c|}{ MANUFACTURERS } \\
\hline Manufacturer A & Food (many product categories) & $\begin{array}{l}\text { In chocolates, it has nearly a } \\
\text { market share of } 70 \%\end{array}$ \\
\hline Manufacturer B & Confectioneries, pastries & $73,5 \%$ \\
\hline Manufacturer C & Drinks (water) & $30,5 \%$ \\
\hline Manufacturer D & Pets food & $26 \%$ \\
\hline Manufacturer E & Dairy products & $60 \%$ \\
\hline Manufacturer F & Food (many product categories) & $\begin{array}{c}\text { In coffee, it has nearly a market } \\
\text { share of } 24,5 \%\end{array}$ \\
\hline Manufacturer G & Detergents & $23,2 \%$ \\
\hline Manufacturer $\mathrm{H}$ & Cookies & $60 \%$ \\
\hline Manufacturer I & Perfumery (sanitary towels, etc.) & $74 \%$ \\
\hline
\end{tabular}

A structured guide was used to initiate the interview through the meetings, which were generally held with the logistics or supply chain directors. In order to increase the reliability of the case study analysis, it was decided to create an 
interview protocol (see table II) and a case study database. Also, other sources of evidence such as newspaper clippings and other articles were used to corroborate and augment evidence.

Table II. Interview protocol

\section{INTERVIEW PROTOCOL}

Q1. How would you define Supply Chain Management?

Q2. What do you think is the difference between Logistics and Supply Chain Management?

Q3. What does SCM mean for your organisation?

Q4. What does SCM mean to other organisations in the grocery sector?

Q5. What do you think are the potential benefits of SCM?

Q6. In general, what do you think are the main barriers to implementing SCM?

Q7. When considering its supply chains, how far upstream and downstream should an organisation consider? How far does your company consider?

Q8. What does ECR mean?

Q9. Is your organisation participating in any ECR initiatives?

If it participates in an ECR initiative:

Q10. For how long?

Q11. How have the results been until now (related to barriers found and benefits achieved)?

With respect to "how to link the data to the research questions", a chain of evidence was established in order to allow any external observer to follow the derivation of any evidence from initial research questions to ultimate case study conclusions.

To determine if a company was internally integrated some factors needed to be present. The most important one was the coordination between the following functions: Purchasing, Manufacturing, Marketing and Distribution. In this paper, coordination between functions has been analysed through two aspects. The first coordination aspect is "if information coming from related functions is considered when taking decisions". In a manufacturing company it means if Production produces what Sales is selling, and if Purchasing buys what Production needs. And, in a retailing company, it means if Purchasing buys what Sales is selling. In our case studies, for example, one retailer was considered not internally integrated because its Purchasing department was doing 
speculative purchases without considering actual sales; its aim was only to obtain low prices. The result of this action was that Purchasing was piling up stock in the Purchasing-Sales frontier.

The second coordination aspect considered was "if the company's departments were acting considering the effects of their decisions on other areas". For example, at one retailer (company 6), the Purchasing director was ordering a product in the quantity needed but with a pallet size that did not fit in the warehousing racks. He had the option to order the product in a pallet with a lower height (which would have fitted in the racks), but he was not doing this because it was "more expensive" (it implied a higher purchasing price). This decision generated a higher handling cost in the warehouse, as every pallet of this product had to be broken and the product repalletised. The Purchasing director did not consider this handling cost because it was a warehousing cost. Probably, the total cost of this purchasing decision (acquisition and handling costs) was higher than the cost of ordering the product in the pallet size suitable for the warehouse, but the fact that each department was acting without considering the effects of its decisions on other departments led to this situation.

Finally, another factor that was showing if a company was internally integrated was the organisational structure. For example, the existence of a "Customer Service" department responsible for the complete order process (Order $\rightarrow$ Analysis of the commercial conditions ${ }^{1} \rightarrow$ Logistics $\rightarrow$ Invoices $\rightarrow$ Payment) showed that the company was internally integrated.

To determine if a company was externally integrated, either upstream or downstream, the variables analysed were: (1) what it understood for SCM and what the firm was doing with respect to it, (2) its participation in ECR pilots and (3) its relationships with other supply chain members. If the definition of SCM 
included integration, coordination and collaboration across organisations and throughout the supply chain, and the firm was implementing it at least with some supply chain members (through its participation in ECR pilots or maintaining collaborating relationships), then the firm was considered to be externally integrated.

\section{Results}

Tables III and IV show the level of internal and external integration achieved by major Spanish manufacturers and retailers.

This analysis suggests that there are companies with different levels of SCM implementation. There are some companies that are still not internally integrated; others that are only internally integrated and, some that being internally integrated have extended this integration to other supply chain members.

Among manufacturers, one (out of nine manufacturers interviewed) was neither internally or externally integrated, another one was internally integrated, six were showing signs of internal and external integration, and one (manufacturer $\mathrm{G}$ ), although not being internally integrated, had some signs of external integration (it was participating in an ECR initiative with one retailer). Regarding retailers, three (out of six retailers interviewed) were not integrated while the rest were internally and externally integrated. Table $\mathrm{V}$ summarises these findings. 
Table III. SCM implementation: Manufacturers' case studies

COMPANY DEGRE OF INTEGRATION

Company A At the moment developing external integration

Company $A$ is internally integrated as Distribution, Planning and Production are coordinated. This company is already working on CRP (Continuous Replenishment Program) with some customers and developing the SCM tools with the aid of an external consultant.

Company B Internally, but not externally integrated

Company B identifies suppliers and customers as members of its supply chain and it is working under a Vendor Managed Inventory environment. However, because there is not any integration in terms of information systems and neither in terms of management (the replenishment is done manually at the customer's house and there is no sharing of information) we consider that this firm is not externally integrated.

Company $\mathrm{C}$ Internally integrated and at the beginning of the external integration

Company $\mathrm{C}$ has developed a Customer Service department that follows the complete order process. It has restructured its internal structure and is at the beginning of the external integration looking for a customer with whom to implement a CRP.

Company D Internally and externally integrated

Company $D$ is internally integrated as Purchasing, Production and Sales are coordinated. Also, the company has recently adopted the SCM view managing suppliers and customers' stocks.

Company E Internally integrated and at the beginning of the external integration

Company $\mathrm{E}$ has a planning process where Marketing, Logistics, Manufacturing and Purchasing participate. This shows it is internally integrated. With respect to external integration, it has participated in some ECR pilots but it is having a hard task finding customers with whom to work on CRP because retailers are giving priority to CRP projects within other product categories.

Company $\mathrm{F}$ Internally and externally integrated

Company $F$ is internally integrated because Purchasing, Manufacturing and Distribution is under the authority and responsibility of the Supply Chain Manager and these areas are coordinated. Its participation in some CRP pilots shows it is externally integrated, at least in some supply chain relationships.

Company G Not internally integrated yet, but some signs of external integration

Not internally integrated yet (structure still strongly departmentalised); however, it is participating in some CRP projects, which shows a slight degree of external integration.

Company $\mathrm{H} \quad$ Not internally and neither externally integrated

Not internally integrated yet (departments working independently), but there are some projects planned to align the organisational structure to the needs of SCM. It has not participated in any CRP project and it neither shows any external integration in terms of systems and management.

Company I Internally and externally integrated

Company I has first internally restructured creating a Customer Service department responsible for the complete order process (from order receipt to delivery to customer). And, it has externally integrated through the management of some important retailers' stock levels through CRP projects. 
Table IV. SCM implementation: Retailers' case studies

COMPANY DEGRE OF INTEGRATION

Company 1 Internally and externally integrated

Purchasing, Warehousing and Distribution are managed according to actual sales. The company analyses the cost of an item taking into account the cost of supply, the warehousing cost and the rest of the logistics costs. These two facts show that this company is internally integrated. It is also externally integrated, at least with some supply chain members, as it is working with them on CRP programs.

\section{Company 2 Not internally and neither externally integrated}

Purchasing and Logistics are still separated and not coordinated. Also, sometimes, there are purchases of products whose stock levels are not at minimum levels, but they are purchased in order to achieve better commercial conditions. These purchasing decisions are made considering the warehousing cost to be zero. These facts show that this firm is not internally integrated. This company is neither externally integrated, as it is not participating in any CRP, and it neither shows any other sign of integration with manufacturers.

Company 3 Not internally and neither externally integrated

Company 3 is strongly departmentalised and it is not participating in any ECR pilot. Therefore, it is not internally integrated and neither externally. Its objective now is to consolidate a recent merger, but, in the future, it wants to participate in the ECR forum and to adopt the SCM approach.

\section{Company 4 Internally and externally integrated}

Its organisational structure shows that it is internally integrated: Supply and Logistics is under the responsibility of the same manager. Purchasing orders are based on actual sales except for some cases where supply problems can be expected. Its objectives are (1) to execute the commercial policy making available the products to be sold and (2) to reduce the total operations cost and achieve a higher efficiency. It is working on CRP with some manufacturers and also on some supply chain reengineering pilots.

\section{Company 5 Internally and externally integrated}

There is not speculative purchasing and orders are made according to sales volumes. Company 5 has externally integrated working on CRP with two manufacturers. It is also working on some supply chain reengineering projects with some manufacturers and Third Party Logistics.

Company 6 Not internally integrated and neither externally integrated

Company 6 is not fully internally integrated because although orders are made according to minimum stock levels, there is also speculative purchasing. Another aspect showing no internal integration is the fact that one manufacturer supplies pallets with a size not suitable for the warehouse. Purchasing could order a suitable size pallet but it does not do that because it would be more expensive (higher acquisition cost). As a result, repalletisation has to be done in the warehouse, but its cost is not considered. It is neither externally integrated as there are no signs of integrated systems or participation in any ECR program. 
Table V. Internal and external integration

\begin{tabular}{lcc}
\hline \multicolumn{1}{c}{ LEVEL OF INTEGRATION } & MANUFACTURERS & RETAILERS \\
\hline \hline No integration & Manufacturer H & Retailer 2 \\
& & Retailer 3 \\
& & Retailer 6 \\
\hline Only internal integration & Manufacturer B & \\
\hline Internal and external integration & Manufacturer A & Retailer 1 \\
& Manufacturer C(*) & Retailer 4 \\
& Manufacturer D & Retailer 5 \\
& Manufacturer E & \\
\hline $\begin{array}{l}\text { No internal integration YET but some } \\
\text { signals of external integration }\end{array}$ & Manufacturer F & \\
\hline
\end{tabular}

$\left(^{*}\right)$ Manufacturer $\mathrm{C}$ is still not externally integrated but it is looking for a customer to work under the ECR philosophy. It is at the beginning of external integration.

These results suggest that apart from manufacturer G, companies are following the integration process proposed by Stevens (see figure 1). Companies usually integrate internally first, and then, extend the integration process to other supply chain members.

These results also suggest that manufacturers, in general, seem to have a higher level of SCM development than retailers. But care has to be taken about generalisation. A survey should be conducted to confirm this statement. The differences between the numbers of manufacturers and retailers that have adopted SCM may be due to the fact that retailers are the dominant party in the relationship. And, consequently, only few have seen the importance of having a more partnership style approach to relationships with their suppliers (i.e. the manufacturers). Manufacturers, on the other hand, as the dominated party, may have been more open to establish a more partnership style of approach to relationships with their customers (i.e. the retailers). The differences found may 
be also due to the fact that all manufacturers in the sample were leaders in their respective product categories, while retailers were all from the same sector. In this sense, if we had interviewed manufacturers from the same product category, we would probably have found more differences (in terms of SCM development) among them.

Another interesting finding is that the biggest retailers are internally and externally integrated, while the smallest ones are not integrated. This could suggest that there is a relationship between the stage of integration and company size. If we look at the manufacturers' results, we can appreciate that most of them are internally and externally integrated. If we had interviewed manufacturers from the same product category we would probably have found that the smallest ones have a lower level of integration. This size-integration relationship should be analysed through a survey.

Regarding the benefits that SCM can bring to a firm (see table $\mathrm{VI}$ ), the general objectives of cost and stock reductions and service improvements were stated by most of the companies. But there were some minor discrepancies between retailers' and manufacturers' responses: First, with respect to the reductions in stock levels, most of the manufacturers believe that higher supply chain collaboration will lead to a reduction in inventory. However, in practice, this result has not been achieved by most of the manufacturers that have implemented ECR. This is due to a lack of critical mass. In order to benefit from stock reductions, manufacturers need to have at least $30 \%$ of their sales under a collaboration program. On the other hand, retailers do not need any critical mass to benefit from stock reductions: All retailers that have implemented an ECR initiative have benefited from stock reductions. 
Table VI. Benefits believed to be related to SCM and benefits achieved in the implementation of ECR practices

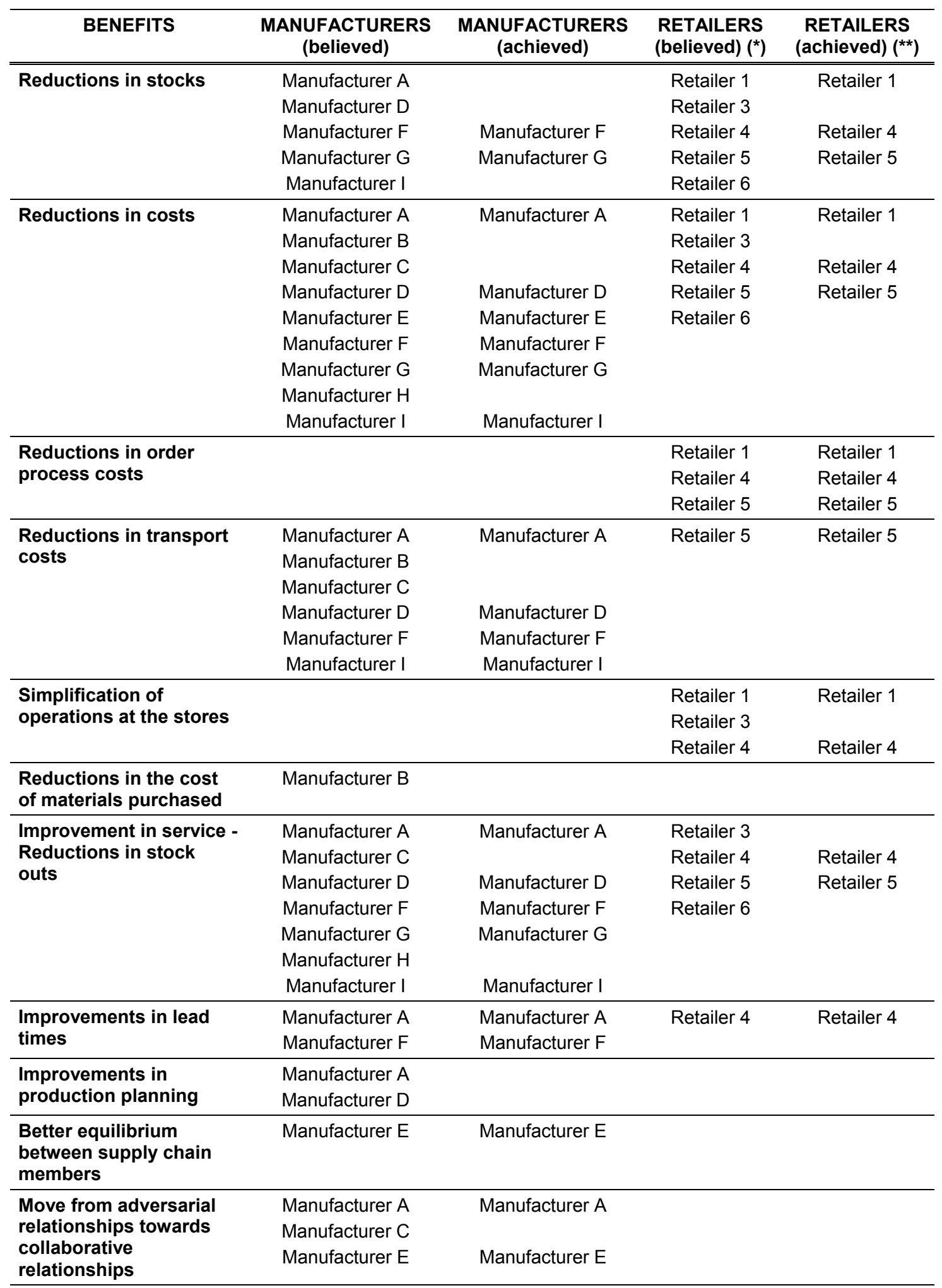

$\left(^{*}\right)$ Retailer 2 was not asked about the benefits related to SCM because it did not have a good understanding of the concept of SCM.

$\left.{ }^{(* *}\right)$ Retailers 2, 3 and 6 and manufacturers $\mathrm{B}, \mathrm{C}$ and $\mathrm{H}$ are not in the column "benefits achieved" because they have not implemented any ECR initiative. 
Second, retailers that have implemented an ECR practice have benefited from reductions in the order process costs, while manufactures have benefited from reductions in the transport costs. Third, most of the retailers working under an ECR program stated that another benefit they obtained was "simplification of operations and higher productivity at the stores (such as no need to have a warehouse at each store). And, fourth, some manufacturers added as benefits related to SCM the following improvements: better lead times and better production planning. However, with respect to this latter aspect (better production planning), it has to be pointed out that manufacturers stated that they had not achieved this expected result because of a lack of critical mass: in order to achieve a better production planning they need to work on ECR with more customers.

There were generally benefits for both parties (manufacturers and retailers) but a common pack of savings that was then divided between both parties did not exist. In the case studies, there is not enough information to determine the reasons for this lack of a real "sharing of benefits".

Table VII summarises the main barriers to implementing SCM. The internal barrier related to culture and attitudes of people working in the company was stated by most of the companies. However, regarding other internal barriers, there were some discrepancies between retailers' and manufacturers' responses. First, some manufacturers, and only one retailer, cited as main barriers: departmental silos and a lack of appropriate information systems and technologies. Second, there are other internal barriers, but these were only stated by retailers: the history and habits of the company, the need of a know how and the need of a minimum size. This latter barrier suggests that in order to establish supply chain collaboration arrangements a company needs to have a 
minimum size. This corroborates what was found in the analysis of the integration process. However, this should be analysed through a survey.

Table VII. Barriers to implementing SCM programs

\begin{tabular}{|c|c|c|}
\hline BARRIERS & MANUFACTURERS & RETAILERS $\left(^{*}\right)$ \\
\hline $\begin{array}{l}\text { History, habits (traditional commercial } \\
\text { relationship) }\end{array}$ & & $\begin{array}{l}\text { Retailer } 3 \\
\text { Retailer } 5\end{array}$ \\
\hline Knowledge (the need of a know how) & & Retailer 1 \\
\hline Size & & Retailer 1 \\
\hline $\begin{array}{l}\text { Information systems and information } \\
\text { technologies }\end{array}$ & $\begin{array}{l}\text { Manufacturer D } \\
\text { Manufacturer F } \\
\text { Manufacturer } \mathrm{H}\end{array}$ & Retailer 5 \\
\hline $\begin{array}{l}\text { Culture and attitudes of people working in } \\
\text { the company }\end{array}$ & $\begin{array}{l}\text { Manufacturer C } \\
\text { Manufacturer D } \\
\text { Manufacturer E } \\
\text { Manufacturer G } \\
\text { Manufacturer H }\end{array}$ & $\begin{array}{l}\text { Retailer } 4 \\
\text { Retailer } 5 \\
\text { Retailer } 6\end{array}$ \\
\hline Departmental barriers & $\begin{array}{l}\text { Manufacturer E } \\
\text { Manufacturer F } \\
\text { Manufacturer I }\end{array}$ & Retailer 5 \\
\hline Lack of trust & $\begin{array}{l}\text { Manufacturer A } \\
\text { Manufacturer E } \\
\text { Manufacturer } \mathrm{H}\end{array}$ & Retailer 4 \\
\hline $\begin{array}{l}\text { Retailers lack a culture of sharing } \\
\text { information }\end{array}$ & Manufacturer $\mathrm{C}$ & \\
\hline $\begin{array}{l}\text { Be afraid of the benefits going only to the } \\
\text { retailer }\end{array}$ & $\begin{array}{l}\text { Manufacturer } \mathrm{C} \\
\text { Manufacturer D } \\
\text { Manufacturer } \mathrm{H}\end{array}$ & \\
\hline $\begin{array}{l}\text { Conditions established by retailers (such } \\
\text { as small batches) }\end{array}$ & Manufacturer $\mathrm{F}$ & \\
\hline
\end{tabular}

$\left.{ }^{*}\right)$ Retailer 2 was not asked about the barriers to implementing SCM because it did not have a good understanding of the concept of SCM.

With respect to the external barriers (barriers related to a supply chain relationship), it has to be pointed out that only one retailer mentioned lack of trust of the other party as a main barrier, while three manufacturers pointed out this obstacle. Other external barriers, mentioned only by manufacturers, are: "retailers have a lack of culture of sharing information"; "we are afraid of the benefits going only to the retailer"; and "retailers have established some conditions, such as delivery of small batches, which difficult the implementation of SCM". These findings suggest that manufacturers see more barriers with 
respect to aspects related to the other party. This could be due to the fact that they are the weakest party in the relationship and they do not trust retailers.

\section{Conclusions and managerial implications}

There are some conclusions that can be derived from this analysis:

Apart from one manufacturer, it seems that companies are following the integration process proposed by Stevens. Companies integrate internally first, and then, extend the integration process to other supply chain members.

* Regarding the benefits that SCM can bring to a firm, the general benefits of cost and stock reductions, and service improvements were stated by most of the firms.

And, finally, regarding the main barriers to implementing SCM firms can find internal and external barriers. One interesting finding was that manufacturers see more difficulties with respect to aspects related to the other party, such as distrust.

It has to be stated that this study has some limitations. It has not considered other important members of the grocery supply chain such as Third Party Logistics, manufacturers' suppliers, etc. Also, as this analysis has been based on personal interviews, all limitations related to this tool, such as subjectivity, should be added. But, despite these limitations, the findings of this study contribute to its exploratory and descriptive aim: to explore the level of SCM implementation in the grocery industry and to describe the logistics integration process.

Integration has emerged as a critical issue in Top Management's agendas, as firms engaged in SCM programs have benefited from cost and stock reductions 
and service improvements. Some managerial implications derived from this work are: With respect to the integration process, firms should internally integrate, and prepare their structures, processes and people before establishing collaborating relationships with their customers and suppliers. Internal integration means coordination between Logistics and other functional areas such as Purchasing, Production and Marketing. It means that decisions in each one of these areas should consider (1) information coming from all of them, and (2) their effects on all of them. And, this requires changes in the organisational structure, processes and people. Regarding the organisational structure, there are some aspects that can help in the integration process: (1) to create a department responsible for all supply chain operations, (2) to establish cross-functional teaming with people from the Purchasing, Marketing, Sales, Production and Logistics areas, and (3) to change the goals and evaluation criteria of each department (for example, the Purchasing Director should not be evaluated according to the purchasing cost, he should be evaluated according to the total cost of ownership, which considers all the costs affected by a purchasing decision). Regarding processes, companies need to establish the cross-functional processes that are related to customer orders. And, finally, regarding people, there is the need to train people in the benefits that internal and external integration can bring.

Integration is not easy to achieve: Firms that initiate an integration process have to overcome some internal barriers, such as resistance to change, the existing company's culture and the firm's habits and history. Firms need also to overcome some external barriers, such as distrust on the other party. To minimise these obstacles, the internal preparation mentioned above plays a key 
role: People's training and change management can substantially reduce these internal and external barriers.

This study has provided us with a higher insight into the SCM practices in the Spanish grocery sector, but it has also guided us in establishing some lines of further research:

- To determine why there is not a real sharing of benefits in the CRP and other ECR practices. Can a model be built in order to make this sharing of benefits available? In that case, which tools and metrics can be used? If this sharing of benefits is due to a lack of culture of sharing benefits, how should organisational and inter-organisational change of management be implemented?

- It has been seen that some companies are adopting a process orientation. In this area, further research should try to identify the key business processes to integrate. Can the Spanish grocery sector be mapped as a group of processes rather than a group of companies?

- Although companies seem to integrate internally first, and then, extend the integration to other supply chain members, we found that one manufacturer had externally integrated without being internally integrated. Further research should analyse if other companies also follow this practice and why.

- It has been seen that the smallest retailers present a lower level of integration than the biggest ones. Further research should analyse if there is a relationship between integration and size. Is size a barrier to implementing SCM as one retailer pointed out? Why? 


\section{References}

[1] Stevens, G.C. (1989), "Integrating the supply chain”, International Journal of Physical Distribution \& Materials Management, Vol.19 no.8, pp. 3-8.

[2] Bowersox, D.J.; Daugherty, P.J.; Dröge, C.L.; Germain, R.N. \& Rogers, D.S. (1992), Logistical Excellence: It's not Business as usual; Digital Press.

[3] Gustin, C.M.; Daugherty, P.J. \& Stank, T.P. (1995), "The effects of information availability on logistics integration", Journal of Business Logistics, Vol.18 no.1, pp. 1-21.

[4] Bowersox, D.J. (1987), "Logistics strategic planning for the 1990's", Council of Logistics Management Fall Conference Proceedings, Oat Brook, Vol.1.

[5] Cooper, M.C.; Ellram, L.M.; Gardner, J. \& Hanks, A. (1997), "Meshing Multiple Alliances", Journal of Business Logistics, Vol.18 no.1, pp. 68.

[6] Christopher, M. (1998), Logistics and Supply Chain Management: Strategies for reducing cost and improving service; Financial Times Pitman Publishing.

[7] Daugherty, P.J.; Sabath, R.E. \& Rogers, D.S. (1992), "Competitive advantage through customer responsiveness", Logistics and Transportation Review, Vol.28 no.3, pp. 257-271; Larson, P.D. (1994), "An empirical study of interorganizational functional integration and total costs", Journal of Business Logistics, Vol.15 no.1, pp. 153-169; Daugherty, P.J.; Ellinger, A.E. \& Rogers, D. (1995), "Information accessibility: Customer responsiveness and enhanced performance", International Journal of Physical Distribution and Logistics Management, Vol.25 no.1, pp. 4-17; Groves, G. \& Valsamakis, V. (1998), "Supplier-customer relationships and company performance", The International Journal of Logistics Management, Vol.9 no.2, pp. 51-63; Stank, T.P.; Crum, M. \& Arango, M. (1999), "Benefits of inter-firm coordination in food industry supply 
chains", Journal of Business Logistics, Vol.20 no.2, pp. 21-41; Stank, T.P.; Daugherty, P.J. \& Autry, C. (1999), "Collaborative planning: Supporting automatic replenishment programs", Supply Chain Management, Vol.4 no.2, pp. 75-85; Ellinger, A.; Daugherty, P.J. \& Keller, S. (2000), "The relationship between marketing/logistics interdepartmental integration and performance in U.S. manufacturing firms: An empirical study", Journal of Business Logistics, Vol.21 no.1, pp. 1-22; Ellinger, A.; Taylor, J.C. \& Daugherty, P.J. (2000), "Programas de reposición automática y niveles de involucramiento: Su impacto en la performance", The International Journal of Logistics Management, Vol.10 no.1, pp. 29-40; Scannell, T.V.; Vickery, S.K. \& Dröge, C.L. (2000), “Upstream supply chain management and competitive performance in the automotive supply industry", Journal of Business Logistics, Vol.21 no.1, pp. 23-48; Stank, T.P.; Daugherty, P.J. \& Ellinger A. (2000), “Integración Marketing/Logística y performance de la empresa", The International Journal of Logistics Management, Vol.10 no.1, pp. 13-27.

[8] Stank, T.P.; Keller, S. \& Daugherty, P.J. (2001), "Supply chain collaboration and logistical service performance", Journal of Business Logistics, Vol.22 no.1, pp. 29-48; Gimenez, C. \& Ventura, E. (2003): "Supply Chain Management as a competitive advantage in the Spanish grocery sector", The International Journal of Logistics Management, Vol. 14 no.1.

[9] Stock, G.N.; Greis, N.P. \& Kasarda, J.D. (1998), "Logistics, strategy and structure: A conceptual framework", International Journal of Operations \& Production Management, Vol.18 no.1, pp. 37-52.

[10] Stevens, G.C. (1989), "Integrating the supply chain", International Journal of Physical Distribution \& Materials Management, Vol.19 no.8, pp. 3-8. 
[11] Cooke, J. (1994), "Logistics quality: part III - beyond quality ... speed", Traffic Management, Vol.33 no.6, pp. 32-39; Fiorito, S.S.; May, E.G. \& Straughn, K. (1995), "Quick response in retailing: Components and implementation", International Journal of Retail \& Distribution Management, Vol.23 no.5, pp. 1221; and Harris, J.K.; Swatman, P.M.C. \& Kurnia, S. (1999), "Efficient Consumer Response (ECR): A survey of the Australian grocery industry", Supply Chain Management, Vol.4 no.1, pp. 35-42.

[12] Ellram, L.M.; La Londe, B. \& Weber, M. (1999), "Retail Logistics", International Journal of Physical Distribution and Logistics Management, Vol.29 no.7/8, pp. 477-494; Fiorito, S.S.; May, E.G. \& Straughn, K. (1995), "Quick response in retailing: Components and implementation", International Journal of Retail \& Distribution Management, Vol.23 no.5, pp. 12-21; Christopher, M. (1998), Logistics and Supply Chain Management: Strategies for reducing cost and improving service; Financial Times Pitman Publishing; and Harris, J.K.; Swatman, P.M.C. \& Kurnia, S. (1999), "Efficient Consumer Response (ECR): A survey of the Australian grocery industry", Supply Chain Management, Vol.4 no.1, pp. 35-42.

[13] Mitchell, A. (1997), "Efficient Consumer Response: A new paradigm for the European FMCG sector", Financial Times Retail \& Consumer Publishing.

[14] Daugherty, P.J.; Sabath, R.E. \& Rogers, D.S. (1992), "Competitive advantage through customer responsiveness", Logistics and Transportation Review, Vol.28 no.3, pp. 257-271; Larson, P.D. (1994), "An empirical study of inter-organizational functional integration and total costs", Journal of Business Logistics, Vol.15 no.1, pp. 153-169; Daugherty, P.J.; Ellinger, A.E. \& Rogers, D. (1995), "Information accessibility: Customer responsiveness and enhanced performance", International Journal of Physical Distribution and Logistics 
Management, Vol.25 no.1, pp. 4-17; Groves, G. \& Valsamakis, V. (1998), "Supplier-customer relationships and company performance", The International Journal of Logistics Management, Vol.9 no.2, pp. 51-63; Stank, T.P.; Crum, M. \& Arango, M. (1999), "Benefits of inter-firm coordination in food industry supply chains", Journal of Business Logistics, Vol.20 no.2, pp. 21-41; Stank, T.P.; Daugherty, P.J. \& Autry, C. (1999), "Collaborative planning: Supporting automatic replenishment programs", Supply Chain Management, Vol.4 no.2, pp. 75-85; Ellinger, A.; Daugherty, P.J. \& Keller, S. (2000), "The relationship between marketing/logistics interdepartmental integration and performance in U.S. manufacturing firms: An empirical study", Journal of Business Logistics, Vol.21 no.1, pp. 1-22; Ellinger, A.; Taylor, J.C. \& Daugherty, P.J. (2000), "Programas de reposición automática y niveles de involucramiento: Su impacto en la performance", The International Journal of Logistics Management, Vol.10 no.1, pp. 29-40; Scannell, T.V.; Vickery, S.K. \& Dröge, C.L. (2000), “Upstream supply chain management and competitive performance in the automotive supply industry", Journal of Business Logistics, Vol.21 no.1, pp. 23-48; Stank, T.P.; Daugherty, P.J. \& Ellinger A. (2000), “Integración Marketing/Logística y performance de la empresa", The International Journal of Logistics Management, Vol.10 no.1, pp. 13-27.

[15] Stank, T.P.; Keller, S. \& Daugherty, P.J. (2001), "Supply chain collaboration and logistical service performance", Journal of Business Logistics, Vol.22 no.1, pp. 29-48.

[16] Gimenez, C. \& Ventura, E. (2003): "Supply Chain Management as a competitive advantage in the Spanish grocery sector", The International Journal of Logistics Management, Vol. 14 no.1. 
[17] Lewis, M.W. (1998), "Iterative triangulation: A theory development process using existing case studies", Journal of Operations Management, Vol.16, pp. 455-469.

[18] Yin, R.K. (1994), Case study research: Design and methods, Sage Publications, USA.

1 Before the order was communicated to the Logistics function, the Customer Service department analysed the commercial conditions (price, delivery terms, etc.) that had been previously negotiated with that customer. 